\title{
A study evaluating knowledge, attitude and practices of practitioners in the medicine department of tertiary care teaching rural hospital with respect to antihypertensives
}

\author{
Jatin Patel*, Andrew Mark, Sanjay K. Date
}

\author{
Department of Pharmacology, Sumandeep Vidyapeeth's, S.B.K.S. M.I. \& R.C., Piparia-391760, Vadodara, Gujarat, \\ India
}

Received: 22 January 2015

Accepted: 8 February 2015

\author{
*Correspondence: \\ Dr. Jatin Patel, \\ E-mail: drjatinpatel1985@gmail.com
}

Copyright: ( $)$ the author(s), publisher and licensee Medip Academy. This is an open-access article distributed under the terms of the Creative Commons Attribution Non-Commercial License, which permits unrestricted non-commercial use, distribution, and reproduction in any medium, provided the original work is properly cited.

\begin{abstract}
Background: The aim of this study was to evaluate knowledge, attitude and practices of practitioners in the medicine department of tertiary care teaching rural hospital with respect to antihypertensives and find out the disparity between the recommended and actual practices for pharmacological management.

Methods: It was survey type of study, carried out using feedback questionnaire related to use of antihypertensives. Total 25 consultants were included in the study.

Results: It was found that in mild hypertension single drug and two drugs in combination were preferred by 15 and 10 practitioners respectively. In moderate hypertension single drug, two drugs in combination, and greater than two drugs were preferred by 3,13 , and 7 practitioners respectively. In severe hypertension two drugs in combination and greater than two drugs were preferred by 16 and 9 practitioners respectively; none preferred single drug. Angiotensin converting enzyme inhibitors /angiotensin receptor blockers, beta blockers, Calcium channel blockers, diuretics were preferred as first line drug by 7, 4, 8, and 16 practitioners respectively. Most commonly preferred combination was Losartan and amlodipine by 16 practitioners. In pregnancy nifedipine was preferred as the first line drug while in elderly diuretics were preferred. In hypertensive patients with age less than 40 years all practitioners preferred ACEIs/ARBs. In diabetics ACEIs/ARBs was preferred by all practitioners. Each practitioner claimed to follow Joint National Committee (JNC) 7 criteria. Cost of drug was an important consideration in all their prescribing patterns. Conclusion: The knowledge, attitudes and practices followed by the practitioners of Dhiraj hospital were satisfactory and guidelines oriented.
\end{abstract}

Keywords: Hypertension, Antihypertensives, JNC 7, Tertiary care practitioners

\section{INTRODUCTION}

Hypertension is a very common disorder, particularly after middle age. It is not a disease in itself, but is an important risk factor for cardiovascular mortality and morbidity. It has been identified to contribute significantly to cardiovascular mortality. ${ }^{1}$ The cutoff manometric reading between normotensives and hypertensives is arbitrary. However, Joint National Committee (JNC) 7 (2003) and WHO-ISH guidelines
(2003) have defined it to be $140 \mathrm{mmHg}$ systolic and 90 $\mathrm{mmHg}$ diastolic, though risk appears to increase at pressure even above 120/80 $\mathrm{mmHg}$. Epidemiological studies have confirmed that higher the pressure (systolic or diastolic or both) greater is the risk of cardiovascular disease. $^{2}$ In 2000 almost one billion patients had hypertension worldwide; it is predicted that prevalence of hypertension will increase by 2025 to approximately $60 \%{ }^{3}$ The studies have also confirmed that reducing BP can substantially decrease cardiovascular risk and all- 
cause mortality. Treatment of hypertension is constantly evolving now, various updated guidelines like JNC 8 have come up for management of hypertension and apart from this various new drugs are available for managing hypertension. ${ }^{4}$ The resultant changes in drug use from practitioner to practitioner may have medical, social and economic implications both for the individual patient and for populations. These differences need to be identified, explained and corrected if need be. Issues of rationality and effectiveness also are important. Therefore, the present study was conducted to evaluate knowledge, attitude and practices of practitioners in the medicine department of tertiary care teaching rural hospital with respect to antihypertensives and find out the disparity between the recommended and actual practices for pharmacological management.

\section{METHODS}

It was survey type of study, carried out among the physicians in the medicine department of tertiary care teaching rural hospital using feedback questionnaire related to use of antihypertensives. Total 25 consultants were included in the study. The study was initiated only after approval by institutional ethics committee of Sumandeep Vidyapeeth.

\section{Statistical analysis}

All data obtained were analyzed using the Microsoft excel software. Descriptive analysis was performed on all the variables to obtain the frequency and percentage.

\section{RESULTS}

It was found that in mild hypertension single drug and two drugs in combination were preferred by 15 and 10 practitioners respectively. In moderate hypertension single drug, two drugs in combination, and >two drugs were preferred by 3,13 , and 7 practitioners respectively. In severe hypertension two drugs in combination and $>$ two drugs were preferred by 16 and 9 practitioners respectively; none preferred single drug.

Angiotensin Converting Enzyme Inhibitors (ACEIs)/Angiotensin Receptor Blockers, beta blockers (ARBs), Calcium Channel Blockers (CCBs), diuretics were preferred as first line drug by $7,4,8$, and 16 practitioners respectively. Most commonly preferred combination was losartan and amlodipine by 16 practitioners, followed by amlodipine and hydrocholothiazide, 7 practitioners and atenolol and amlodipine by 2 practitioners.

In pregnancy methyldopa, nifedipine, and labetalol were preferred as first line drug by 2,13 , and 10 practitioners respectively. In elderly diuretics, ACEIs/ARBs, and CCBs were preferred as first line drug by 12,10 , and 3 practitioners respectively; none preferred beta blockers. In hypertensives $<40$ years age all practitioners preferred
ACEIs/ARBs. In diabetics ACEIs/ARBs was preferred by all practitioners. Each practitioner claimed to follow Joint National Committee (JNC) 7 criteria. Everyone was aware of availability of JNC 8 criteria but none was aware of the criteria or the difference between JNC 7 and JNC 8. All were considerate about the cost of drug.

\section{DISCUSSION}

Hypertension being highly prevalent and also being an important risk for cardiovascular diseases must be controlled to target levels. A study by Kale Anand in Karnataka showed that the most frequently prescribed antihypertensive medications were: Calcium channel blockers (49\%) followed by diuretics (43.5\%), angiotensin converting enzyme inhibitors $(29.5 \%)$ beta blockers $(29 \%)$ and angiotensin receptor blockers $(21 \%){ }^{5}$ In our study we found that Angiotensin Converting Enzyme Inhibitors (ACEIs)/Angiotensin Receptor Blockers, beta blockers (ARBs), Calcium Channel Blockers $(\mathrm{CCBs})$, diuretics were preferred as first line drug by $7,4,8$, and 16 practitioners respectively. Hence in our set up physicians preferred ACEIs/ARBs over CCBs. This was in concordance with study by Kaur S et al. which reported that Angiotensin Converting Enzyme inhibitors (ACE inhibitors) and calcium channel blockers were the most commonly prescribed antihypertensive drugs $\left(33.8 \%\right.$ and $30.7 \%$ respectively). ${ }^{6}$ ACEIs/ARBs have advantage over other group of drugs in that they not only decrease blood pressure but they also prevent cardiac remodelling in the those with left ventricular failure, additionally they have better safety profile and are also renoprotective. ${ }^{2}$ This may be reason for physicians to prefer ACEIs/ARBs over other group of drugs.

Not only that they also have renoprotective in patients with diabetes and in those who have developed microalbuminuria, they may even reverse it. [2] This may be the reason for preference of ACEIs/ARBs by all practitioners. Similar results were reported by Johnson ML and Singh $\mathrm{H}$ in their study on antihypertensives in diabetics and showed that over $60 \%$ of patients were receiving Angiotensin-Converting Enzyme Inhibitors (ACEI) or Angiotensin Receptor Blocker (ARB); while in the study by Kale it was seen that hypertensive cases with co-existing diabetes mellitus type II, were mostly prescribed diuretics (43.8\%) followed by angiotensin converting enzyme inhibitors $(40.4 \%) .^{5}$

In the study by Kale et al. $51 \%$ of patients were on multiple drug therapy, the most favored fixed drug combination being diuretics with angiotensin receptor blockers $(25.4 \%) .^{5}$ In our study we found that in mild hypertension single drug and two drugs in combination were preferred by 15 and 10 practitioners respectively. In moderate hypertension single drug, two drugs in combination, and >two drugs were preferred by 3, 13, and 7 practitioners respectively. In severe hypertension two drugs in combination and >two drugs were preferred by 16 and 9 practitioners respectively; none preferred 
single drug. Using a combination in patients with mild hypertension is irrational. One should begin with one drug, however, if the patients pressure is not controlled with single drug, then escalation of dose may be needed, or a second drug may be added, this decrease the side effects that may occur with high dose of one drug. ${ }^{2}$ When two antihypertensives are being prescribed to the patient then a fixed dose combination of two drugs may be used. ${ }^{2}$

In our study in elderly CCBs, ACEIs/ARBs, diuretics were preferred as first line drug by 3,10 , and 12 practitioners respectively; none preferred beta blockers. Stokes GS states that the choice of antihypertensive drug therapy in elderly is influenced by concomitant disease and previous medication history, but will typically include a thiazide diuretic as the first-line agent; to this will be added an angiotensin inhibitor and/or a calcium channel blocker. Beta blockers are not generally recommended, in part because they do not combat the effects of increased arterial stiffness. ${ }^{8}$ In pregnancy methyldopa, nifedipine, and labetalol were preferred as first line drug by 2,13 , and 10 practitioners respectively. This was in concordance to JNC VII guidelines. ${ }^{9}$ In hypertensives $<40$ years age all practitioners preferred ACEIs/ARBs. This was similar to the guidelines of JNC VII and that of university of Cambridge. ${ }^{9,10}$

Everyone was aware of availability of JNC 8 criteria but none was aware of the criteria or the difference between JNC 7 and JNC 8, which is absurd as updated guidelines give an insight into newer developments and therefore must always be followed. All were considerate about the cost of drug, which is a good sign as the therapy for hypertension is lifelong and therefore cost can have severe implication on compliance.

We conclude that overall the practices followed by the practitioners of Dhiraj hospital were satisfactory and guidelines oriented. However cause of concern was use of combination drugs right from the beginning for mild hypertension, which should be avoided. Updated guidelines must always be followed.

We conclude that prescribing pattern was satisfactory however updated guidelines should be followed.

\section{Limitations}

As it was the survey study conducted among practitioners of Vadodara it may not represent the behaviour of the practitioners at other places. A prospective direct interview would be better to obtain informative data. Future studies can be carried out in different parts of India, including urban and rural areas. Exact figures were difficult to quote by different practitioners. This resulted in inaccurate or incomplete information. We could have missed much information because of practitioner's reluctance to reveal the details of his prescribing pattern.

\section{ACKNOWLEDGEMENTS}

We would like to express our gratitude to all the respondents for spending their valuable time to answer our questionnaire that helped us to successfully complete our study. Authors are also thankful to the institutional ethical committee of Sumandeep Vidyapeeth that permitted to conduct such a survey study.

Funding: No funding sources

Conflict of interest: None declared

Ethical approval: The study was approved by the institutional ethics committee of Sumandeep Vidyapeeth

\section{REFERENCES}

1. Johnston A, Stafylas P, Stergiou GS. Effectiveness, safety and cost of drug. Br J Clin Pharmacol. 2010:70(1);320-34.

2. Tripathi KD. Antihypertensive drugs. In: Tripathi KD, eds. Essentials of Medical Pharmacology, 6th ed. New Delhi: Jaypee Brothers Medical Publishers; 2009: 539-573.

3. Kearney PM, Whelton M, Reyonolds K. Muntner P, Whelton PK, He J. Global burden of hypertension: analysis of worldwide data. Lancet. 2005;365:21723.

4. Khan NA, Hemmelgarn B, Herman RJ, Rabkin SW, McAlister FA, Bell CM, et al. Canadian hypertension education program. Can $\mathrm{J}$ Cardiol. 2008;24(6):465-75.

5. Kale A, Maniyar YA. Prescribing patterns of antihypertensive drugs in a tertiary care hospital. Sch Acad J Pharm. 2013;2(5):416-8.

6. Kaur S, Gupta S, Kumar D, Lal M, Gilani Z. Prescribing pattern of antihypertensive drugs in a tertiary care hospital in Jammu: a descriptive study. JK-Practitioner. 2012;17(4):38-41.

7. Johnson ML, Singh H. Patterns of antihypertensive therapy among patients with diabetes. J Gen Intern Med. 2005;20:842-6.

8. Stokes GS. Management of hypertension in the elderly patient. Clinical interventions in aging. Dove Press. 2009;7:379-89.

9. NHLBI Hypertension Guidelines. JNC VIII guidance, 2014. Available at: http://www.nhlbi.nih.gov/guidelines/hypertension/jn c8full.htm.

10. Clinical Pharmacology Unit. Guidelines for the management of hypertension. University of Cambridge. Available at: http://www.clinpharm.medschl.cam.ac.uk/public/BP Guidelines.pdf. Accessed 7 November 2014.

DOI: $10.5455 / 2320-6012$. ijrms20150336

Cite this article as: Patel J, Mark A, Date SK. A study evaluating knowledge, attitude and practices of practitioners in the medicine department of tertiary care teaching rural hospital with respect to antihypertensives. Int J Res Med Sci 2015;3:715-7. 